\title{
Rootstock Breeding: An Analysis of Intractability
}

\author{
Peter Cousins ${ }^{1}$
}

\author{
U.S. Department of Agriculture, Agricultural Research Service, Plant Genetic Resources Unit, Geneva, NY 14456
}

\begin{abstract}
Breeding rootstocks for fruit crops is slower than scion breeding in the same species. This is due to the testing requirements of rootstocks that reduce the opportunity for comprehensive first tests on individual plants and to expanding selection criteria for rootstocks. Rootstock breeding is a relatively new discipline of fruit crop improvement and novel functions of rootstocks still are being understood and developed; this increases the requirements of rootstocks without diminishing the testing requirements.
\end{abstract}

Why is breeding rootstocks for fruitcrops considered intractable and how is breeding rootstocks for fruit crops fundamentally different and more difficult than breeding fruiting cultivars of those same crops? The short answer is that rootstock breeding differs from fruiting cultivar development in the length of the breeding cycle and in the history and scope of improvement

\section{Rootstock Breeding Progress}

Rootstock breeding progress often is slow compared to breeding fruiting cultivars of tree and vine crops, which in turn is slow compared to annual crops. While the species used in rootstock breeding usually have a reproductive cycle that is close to that of the fruiting cultivars for a given crop, rootstock breeding is still more complex. Selecting candidate rootstocks from populations is more difficult than selecting candidate fruiting cultivars because the testing cycle for rootstocks is longer than for fruiting cultivars. A step-by-step comparison of a generic rootstock and fruiting cultivar program is illustrative of the essential differences.

In the first year, the crosses are made and the seeds are collected. The following spring they are sown. The seedlings begin to grow; they may be screened for pest or disease resistance or for molecular markers in linkage disequilibrium with some trait of interest, but to this point no substantive differences between a rootstock and fruiting cultivar program are evident.

After a few years, the population in the fruiting cultivar program begins to bear. Fruiting characteristics are observed and desirable individuals are selected. There are likely to be at least several years of observations before the final selections are made, with testing of a small number of plants and then larger numbers coming before replicated trials across the intended region of cultivation.

In contrast, the rootstock population grows and then must be entered into a long testing program. The goal is an improved rootstock, so it must be grafted to a suitable scion. However, if we graft the seedling, usually that individual would be lost for further propagation. So the individual seedlings are propagated to provide multiple plants for testing and the progeny plants are then grafted. The process of producing multiple plants for testing can take several years. Then the candidate rootstocks, now grafted, are planted and their performance is evaluated. Here, the evaluation of rootstocks returns to the path taken by fruiting cultivars.

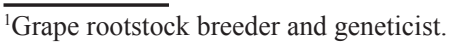

Testing the rootstocks once sufficient material is available for replicated plantings need not be more difficult than the testing of fruiting cultivars, but candidate rootstocks need to be multiplied before this step can be accomplished. The reduced opportunity for individual plant first tests distinguishes rootstock breeding from fruiting cultivar breeding.

There are exceptions to the generally reduced opportunity for individual plant first testing in rootstock breeding. Some Prunus rootstocks, for example, can be propagated from root suckers, and so a grafted plant would not necessarily be lost to propagation. In this case, the testing of grafted plants could be accomplished on individuals. In species in which suckers from a rootstock could be rooted and used to replicate selected candidate rootstocks from the first test planting, individual nonreplicated plants could be used in testing. Leaving rootstock suckers is undesirable, however, as vigorous suckers interfere with orchard management and compete with scion shoots. Sexually propagated rootstock cultivars (seedling rootstocks) dominate for many fruit crops and have an even more intractable testing regime. The individual seedlings from hybridization are grown until maturity and then their progeny seedlings are tested for suitability as rootstocks.

The second area in which rootstock breeding differs from that of fruiting cultivars improvement is history and scope of improvement. Rootstock use itself is not new. Rootstocks have been used for thousands of years to facilitate clonal propagation of fruit trees. However, for most of that time, rootstock cultivars were not the specific object of breeding. Now rootstocks are being asked to provide an increasing fraction of the functional aspect of the tree.

\section{Historical Context}

Our horticultural forbears began a trajectory of selection for improved fruiting cultivars on which we largely maintain. Speaking generally, larger and sweeter fruit are better. The ability to be processed, shipped, or stored is desirable. High yield is better than low yield. The goals of today's fruiting cultivar breeders would likely be familiar to our progenitors and the quality and advantage of modern cultivars instantly recognized.

Imagine introducing a horticulturist from the distant past to a comprehensive fruit breeding program. After being impressed by the fruiting cultivarimprovementblocks, we head over to the rootstock selections and explain the importance of clonal propagation ability, dwarfing, branch angles, and rootstock resistance to bacteria, vi- ruses, nematodes, and fungi. Our guest is likely to respond with puzzlement. While the improvement of fruiting cultivars encompasses a certain amount of instinct, rootstock breeding is largely nonintuitive. Rootstock breeding directions are many and varied and their application requires a better understanding the nature of the interaction of scion, rootstock, and environment.

Rootstocks were first used for propagation purposes. Fruit tree cultivars were grafted onto seedling grown rootstocks to increase uniformity of the scions through clonal propagation. Protection against pests and diseases, adaptation to particular growing conditions, impact on tree form and yield and other rootstock features only later became important considerations for rootstock selection. Additional impacts of rootstocks on scions still are being tested and acknowledged and novel impacts generated. As the utility of rootstocks in fruit crop management was recognized, selection of rootstocks for particular characteristics became more important. As more and more is requested of the rootstock, the value of uniformity of the rootstock increases concomitantly.

Rootstock breeding and selection is a young discipline. Breeding, selection, and sorting out of seedling and clonal types for many temperate fruit crop rootstocks substantially began in the 19th century (Ferree and Carlson, 1987; Layne, 1987; Lombard and Westwood, 1987; Wertheim, 1998; Winkler, et al. 1974; Gerber Products Co., 1963). In contrast, the fruit crops themselves have been grown and selected for thousands of years. This late startpositions rootstock breeding behind scion improvement, lending an appearance of intractability. Rootstocks are hard to breed because we are behind in generations compared to fruiting cultivars. Has there not been an increase in the characteristics for which fruit crop scion varieties are bred? Yes, certainly; recognition of the importance of pests and diseases and the increasing importance postharvest quality in particular have widened the responsibility for improvement. However, because rootstock breeding and selection in general is a new branch of horticulture, the increase in the breadth of rootstock requirements has been proportionately greater than for scion improvement.

\section{Rootstock Breeding Objectives}

Stone fruit and pome fruit are good case studies of increasing demands placed on rootstocks. In particular, clonal propagation of pome fruit through grafting has been carried out for thousands of years (Brown, 1975; Wertheim, 1998) and stone and pome fruit are character- 
istically difficult to propagate from cuttings using traditional methods (especially dormant hardwood cuttings). Historically, the most commonly used rootstocks were seed propagated and provided the means to clonally propagate the scion. Resistance to pests and diseases and induction of dwarfing tree forms were early targets of rootstock breeding programs. Modern apple rootstock breeding programs might cover resistance to fire blight, woolly apple aphid, apple replant disease, crown rots, and voles; level of burrknot production; propagation ability, latent scion virus tolerance; rooting depth, mineral nutrient uptake, and scion fruit quality; bearing precocity; level of dwarfing; and branch angles (Brown, 1975; Ferree and Carlson, 1987; Wertheim, 1998), with a comparable breadth of improvement responsibilities for pear and stone fruit rootstock breeding programs.

With more desirable features incorporated into the rootstock, the value of uniformity increases. While seed propagation has been the rule for many fruit crop rootstocks, with more and more features, incorporating all of these into a sexually propagated rootstock is viewed as increasingly challenging. The desire for increased uniformity in rootstocks reflects a trend for increasing demands on rootstocks. In some crops, such as grape, all rootstocks are clonally propagated for nursery production. At the other end of the spectrum are crops such as pecan and persimmon, in which seedling rootstocks are nearly universal. Many temperate fruit and nut crop rootstocks, including those for stone and pome fruit, almonds, and walnuts, include both seed propagated and clonally propagated cultivars. However, the trend is towards increased uniformity in rootstocks and this is likely to be achieved clonally. Clonal propagation ability in many fruit and nut crop rootstocks is a relatively novel feature for selection, especially those in which seedling propagated rootstocks provided an avenue to compensate for intractable propagation of the scion cultivars.

The intractability of rootstock breeding and use (even apart from breeding) is demonstrated by the examples of grape, olive, and fig. These fruit crop species typically root easily from dormant hardwood cuttings. Rootstock use in grapevine was precipitated by the introduction of phylloxera, an insect that feeds on and damages grapevine roots, to Europe in the mid-1800s; growers adopted rootstocks to protect their vines against phylloxera. Grapevine cultivation was significantly complicated by the move to rootstocks, as grafted vines are more expensive than own-rooted vines and their specialized production encouraged the development of nurseries to specifically handle this material. Most cultivated grapevines in areas where phylloxera are not considered a significant risk are still grown on their own roots (Winkler et al., 1974). Olive trees are readily propagated from hardwood cuttings. Rootstocks are available (Hartman and Beutel, 1979), particularly to provide protection against Verticillium wilt, but their use is limited. Candidate fig rootstocks have been identified (Storey, 1975), but again are not the standard (Hartman and Beutel, 1979). Although there is genetic variation for useful rootstock characteristics in these fruit crops, it is only sought as a last resort. Rootstocks themselves are difficult and expensive to evaluate, develop, and use and this is even more true of their breeding and improvement.

Rootstocks increasingly are called upon for management of scion problems. Pierce's disease of grapevines is caused by a xylem-limited bacterium (Xylella fastidiosa) that is transmitted by insects. Trials have been conducted to determine the impact of the rootstock on what is indisputably a scion disease (Cousins and $\mathrm{Lu}$, 2002; Ren and Lu, 2002). The attraction of this approach is that a rootstock that ameliorates Pierce's disease symptoms would be useful for many susceptible scion cultivars. However, there are grape scion cultivars that are resistant to Pierce's disease - why not use these in breeding resistant scion cultivars directly? Dwarfing rootstocks, used effectively in several tree fruit crops, reduce tree size, but tree size is also a feature of the scion cultivar itself and genetic dwarfing and devigoration is present in scion germplasm as well (Brown, 1975; Fideghelli, et al, 2003; Hesse, 1975; Wertheim, 1998). Other aspects of scion physiology may be affected directly or indirectly by the rootstock variety, including bloom date and winter cold hardiness (Layne, 1975; Wertheim, 1998). Relying on rootstocks as primary drivers of scion disease response and physiology simplifies scion variety selection and breeding by transferring this responsibility to rootstock breeders.

Fruit crop rootstocks have been targeted for the delivery of transgene products to the scion(Meredith and Dandekar, 2003) following the idea that the transformation of a rootstock would simplify the implementation of such a technology, since only a few rootstocks would need to be transformed rather than all potential scion cultivars. This potential new role of fruit crop rootstocks will contribute to the complexity of rootstock breeding, shifting additional responsibility for fruit tree improvement towards the rootstock. Whether through transgenic or conventional improvement, the trend toward increasing reliance on the rootstock is logical, yet still results in increased intractability. These are difficult traits with which to work, so scion breeders seek to shift this responsibility towards rootstocks.

The trend in rootstock breeding is to incorporate more traits into the roster of ideotypic features. Propagation ability, once barely considered in many crops because of the acceptance of seed propagated rootstocks, has become critical due to sophisticated multifaceted clonal rootstocks. Resistance to replant disease complexes and syndromes, which may involve fungi, bacteria, and nematodes, are increasingly a target of rootstock breeding programs for fruit crops as the use of methyl bromide and other preplant soil treatments is regulated and reduced. Plant size reduction is a key component for high-density, ladder-free, and mechanized orchard systems (Wertheim, 1998). Production trends are towards reduced chemical inputs (including fertilizers and pre and postplant pesticides), fewerpasses by hand-labor crews, and higher production with more plants per unit area. Rootstocks of the future must accommodate and facilitate these trends.
Can the intractability of rootstock breeding be reduced? Improved testing practices and indirect selection will accelerate the pace of rootstock breeding, but the dichotomy between scion and rootstock selection defined by the essential lack of comprehensive first tests on individual plants is likely to remain unchanged. This key difference between fruit crop rootstock and scion breeding, particularly with regard to evaluation, reflects the distinct roles that scions and rootstocks fill in fruit crop production.

\section{The Future}

Rootstock breeding and development will continue to proceed more slowly relative to scion breeding in the same fruit crops. An increasing number of useful characteristics and features will be viewed as desirable once the ability of rootstocks to condition these traits is understood - this applies not only to those intuitively related to rootstock function, such as resistance to soil borne pests and diseases, but also to those less clearly linked to rootstock, such as apparent scion winter hardiness. Rootstocks that deliver specific novel or rare functions to the plant are sought because of the frequent broader utility of rootstock varieties than scion varieties. More goals for breeding programs will increase the intractability of rootstock improvement.

\section{Literature Cited}

Brown, A.G. 1975. Apples, p. 3-37. In: J. Janick and J.N Moore (eds.). Advances in fruit breeding. Purdue Univ. Press, West Lafayette, Ind.

Cousins, P. and J. Lu. 2002. Rootstock variety influence on Pierce's disease symptoms in grafted Chardonnay (Vitis vinifera L.) grapevines, p. 145-146. In: Proc. 2002 California Pierce's Disease Res. Symp. Calif. Dept. Food Agr. Dec. 2002, Coronado, Calif.

Ferree, D.C. and R.F. Carlson. 1987. Apple rootstocks, p. 107-143. In: R.C. Rom and R.F. Carlson (eds.). Rootstocks for fruit crops. Wiley, New York.

Fideghelli, C., A. Sartori, and F. Grassi. 2003. Fruit tree size and architecture. Acta Hort. 622:279-293.

GerberProducts Company. 1963. Literature survey of fruit tree rootstocks. Gerber Products Co., Fremont, Mich.

Hartmann, H.T. and J.A. Beutel, 1979. Propagation of temperate-zone fruit plants. Div. Agr. Sci. Univ. Calif., Berkeley, Lflt. 1103.

Hesse, C.O. 1975. Peaches, p. 285-335. In: J. Janick and J.N. Moore (eds.). Advances in fruit breeding. Purdue Univ. Press, West Lafayette, Ind.

Layne, R.E.C. 1987. Peach rootstocks, p. 185-216. In: R.C. Rom and R.F. Carlson (eds.). Rootstocks for fruit crops. Wiley, New York.

Lombard, P.B. and M.N. Westwood. 1987. Pear rootstocks, p. 145-183. In: R.C. Rom and R.F. Carlson (eds.) Rootstocks for fruit crops. Wiley, New York.

Meredith, C.P. and A. Dandekar. 2003. Directing potential anti-Xylella gene products to the xylem of transgenic grapevines, p. 23-25. Proc. 2003 California Pierce's Disease Res. Symp. Calif. Dept. Food Agr. 8-11 Dec. 2003, Coronado, Calif.

Ren. Z. and J. Lu. 2002. Muscadine rootstock increased the resistance of Florida hybrid bunch grape cultivarcv. Blanc du Bois to Pierce's and anthracnose diseases. Proc. Fla. State Hort. Soc. 115:108-110.

Simons, R.K. 1987. Compatibility and stock-scion interactions as related to dwarfing, p. 79-106. In: R.C. Rom, and R.F. Carlson (eds.). Rootstocks for fruit crops. Wiley, New York

Storey, W.B. 1975. Figs, p. 568-589. In: J. Janick and J.N. Moore (eds.). Advances in fruit breeding. Purdue Univ. Press, West Lafayette, Ind.

Wertheim, S.J. 1998. Rootstock guide: Apple, pear, cherry, european plum. Fruit Res. Sta., Wilhelminadorp, The Netherlands.

Winkler,A.J., J.A.Cook, W.M. Kliewer, and L.A. Lider. 1974. General viticulture. Univ. Calif. Press, Berkeley. 